\title{
Toxicity assessment of dimethyl carbonate following 28 days repeated inhalation exposure
}

\author{
Dongseok Seo ${ }^{1, *(D)}$ \\ ${ }^{1}$ Toxicological Study Department, Occupational Safety and Health Research Institute, KOSHA, Korea \\ *Correspondence: seods@kosha.or.kr
}

Received: April 21, 2021 Accepted: June 10, 2021

\begin{abstract}
Dimethyl carbonate (DMC) has been used as a reagent in methylation reactions, can be used as paints, coatings, and adhesives, and is a chemical that is being used increasing, which poses a health hazard to workers who handle it. So, the toxic reactions of F344 rats with inhalation exposure to 600, 1600, and 5000 ppm concentrations for 6 hours, 5 days a week, 4 weeks was evaluated. During the exposure period, general signs were observed, body weight and food consumption were measured, and hematologic and blood biochemical tests, organ weight measurements, necropsy, and histopathological examination were performed after the end of exposure. During the exposure period, dimethyl carbonate was exposed to an average of $599.26 \pm 31.40,1614.64 \pm 80.79$ and $5106.83 \pm 297.13 \mathrm{ppm}$ in the chambers of the T1, T2 and T3 test groups, respectively. During the test period, general signs, weight change, food consumption, organ weight measurement, necropsy, and histopathological examination did not show any effects related to exposure to the test substance. However, as a result of blood and blood biochemical tests, an increase in AST, ALP, APTT, and PT levels was observed. From these results, it is judged that liver is the target organ when repeated inhalation exposure of dimethyl carbonate, the test substance, for 4 weeks, and the exposure-related effects of the test substance were observed at PT and ALP levels up to $600 \mathrm{ppm}$ exposure concentration, but NOEC (No Observed Effect Concentration) was determined to be less than $600 \mathrm{ppm}$ because it was not judged as an adverse effect.
\end{abstract}

\section{Keywords: Dimethyl carbonate, Inhalation exposure, Toxicity, NOEC}

\section{Introduction}

Among the dialkyl carbonate compounds, dimethyl carbonate (DMC) is a colorless, odorless liquid at room temperature and has recently attracted a lot of attention as one of the "environmentally friendly chemical products". DMC, also known as carbonic acid, dimethyl ester and methyl carbonate, is a promising industrial chemical used in a variety of applications [1]. DMC is an organic compound classified as a carbonate ester with the formula $\mathrm{OC}\left(\mathrm{OCH}_{3}\right)_{2}$. It is a chemical that is produced in the United States over 1 million pounds per year; Kowa corporation has proposed use to increase from 2 to 5 million pounds per year [2].

It is a fast evaporating solvent with polar and hydrogen bonds, which can be effective in replacing esters, glycol ethers and ketones in formulations. In addition to being a solvent, there are potential uses as methylating agents and chemical intermediates for use in the production of diphenyl carbonate, isocyanate, allyl diethylene, glycol carbonate, and carbamate pesticides. We are also interested in using this compound as a fuel oxygen additive and as a solvent for lithium battery electrolytes in the battery industry $[3,4]$. Recently, it was not classified as a Volatile Organic Compound (VOC) according to the clean air act in 2009 by the US EPA, so its use as a solvent has increased. This ruling is based on the fact that DMC is not classified as a hazardous air pollutant and has a low probability of ozone formation. As awareness of environmental protection has increased, low-pollution products with low toxicity have become a trend. The manufacture of solvent-based paints requires a lot of organic solvents, most of which have some degree of toxicity, including aliphatic hydrocarbons, aromatic hydrocarbons, esters, ketones and alcohols. DMC has been proposed as a low-toxic solvent for paints, inks, and adhesives that can replace currently used toluene, ethyl acetate and butyl acetate [5].

Additionally, DMC can be considered a green reagent because it is easily biodegradable, with a low potential to bio-accumulate or be persistent in the environment $[6,7]$. Due to this classification, DMC has increased the preference for use in some fields and as a replacement for other solvents such as methyl ethyl ketone, tert-butyl acetate, and parachlorobenzotrifluoride [5], and other methylating reagents including phosgene, methyl chloroformate, iodomethane, and dimethyl sulfate [8].

DMC is hydrolyzed by esterases in the body to produce carbon dioxide, methanol, formaldehyde, and formic acid as metabolites [2]. Toxicity of DMC is thought to be caused by these metabolites. Toxicological data for DMC are very limited, 
and long-term chronic exposure studies have not been conducted. DMC has low acute oral toxicity (LD50 rat = 12,900 mg/kg, $\mathrm{LD}_{50}$ mouse $=6000 \mathrm{mg} / \mathrm{kg}$ ), and was found to be negative in mutagenicity tests (I.e., Ames and Comet analysis in vitro) performed on L-929 mouse fibroblasts [9]. As a result of a developmental toxicity test conducted by inhalation exposure of DMC to the mated female mice at a concentration of up to 3000 ppm per day for 6 hours, weight loss, growth retardation, and deformity of the mater and fetus were observed, so NOAEL (No Observed Adverse Effect Level) was confirmed as 1000 ppm [10,11]. This was almost the same as methanol (NOAEL 1000 ppm), a major metabolite of DMC [12]. From very limited human data, it is suspected that DMC is slightly toxic upon ingestion [13, 14], but no data are available on chronic exposure to humans. However, toxicity data are available for the metabolites of DMC, methanol, formaldehyde, and formic acid [1517].

Although the test substance of this study, DMC, is highly likely to be exposed to workers who handle it and general people due to its high production volume, toxicity by repeated exposure has not been identified yet. Therefore, this study was conducted to evaluate the toxicity of DMC by inhalation exposure.

\section{Materials and Methods}

\section{Test article}

Dimethyl carbonate (DMC) [CAS No. 616-38-6] was purchased from SAMSHUN Pure Chemical Inc. and its physicochemical properties are as follows:

Molecular formula :

Molecular weight :

Structural formula :

Log pow :

Solubility in/miscibility with water :

Vapor pressure :

Dynamic viscosity :

Relative density :

Melting point/range :

Boiling point/boiling range :

Flashpoint :

Flammability (solid, gaseous) :

Selfignition temperature :

Explosion limits :
C3H6O3

$90.0779 \mathrm{~g} / \mathrm{mol}$<smiles>[10BH]OC(=O)O[10BH2]</smiles>

$0.354\left(\right.$ at $\left.20^{\circ} \mathrm{C}\right)$

$114.7 \mathrm{~g} / \mathrm{l}\left(\right.$ at $\left.20^{\circ} \mathrm{C}\right)$

$7570.4 \mathrm{~Pa}$ at $25^{\circ} \mathrm{C}$

$0.585 \mathrm{mPa} . \mathrm{s}$ (at $20^{\circ} \mathrm{C}$ )

1.0633 at $25^{\circ} \mathrm{C}$

$4.65{ }^{\circ} \mathrm{C}$ at atmospheric pressure

$90.35{ }^{\circ} \mathrm{C}$ at atmospheric pressure

$16.7^{\circ} \mathrm{C}$ (closed cup) at atmospheric pressure

highly flammable

$458^{\circ} \mathrm{C}$ at atmospheric pressure

Lower: $4.22 \%$, Upper: $12.87 \%$

\section{Exposure method of test article}

After putting the test substance into a gas generator (liquid vapor generator, LVG-04-A, HCT Co., Korea) connected to a constant temperature water tank set at a constant temperature as shown in (Figure 1), and the clean air was blown in to vaporize the test substance. The vaporized vapor was prevented from condensing by passing through a cooling condenser set lower than room temperature. The vaporized test substance and clean air were mixed and supplied into the whole-body inhalation toxicity chamber (WITC14M, HCT Co., Korea) at the set concentration. The control group supplied only clean air that did not contain the test substance, and maintained the same environment as the test groups. 


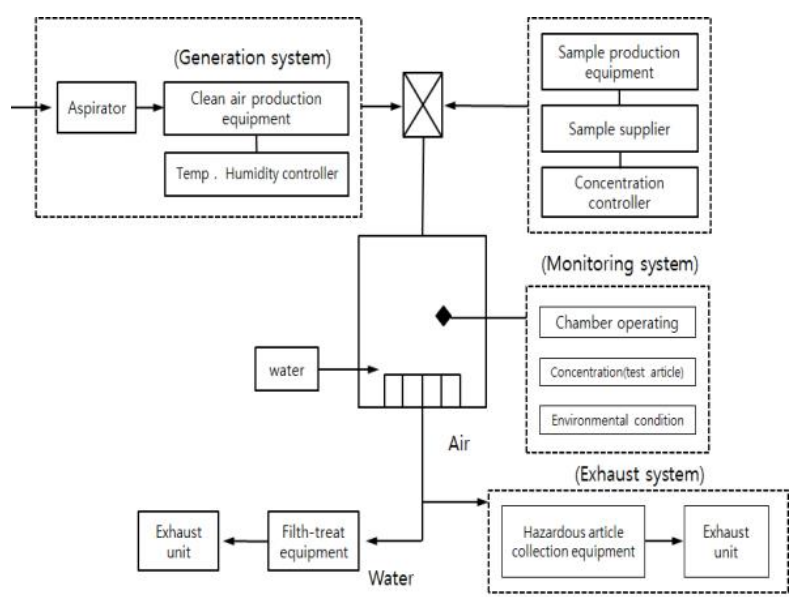

Figure 1. A schematic diagram of monitoring the concentration of test substances and the environment in the inhalation exposure chamber.

\section{Analysis of analytical concentration}

The concentration of DMC in the chamber was analyzed by gas chromatography (TRACE1310, Thermo Scientific, USA) through a sampling device connected near the breathing area of the animal. The frequency of analysis was measured at least three times per test group per day during the exposure period. Gas chromatography analysis conditions are as follows: flame ionization detector (FID), column (TG-5MS, Length 30m, ID $0.25 \mathrm{~mm}$, film $0.25 \mu \mathrm{m}$, max temp 330/250 ${ }^{\circ} \mathrm{C}$, oven temperature $180^{\circ} \mathrm{C}$, injection temperature $130^{\circ} \mathrm{C}$, detector temperature $250^{\circ} \mathrm{C}$, injection volume gas sample $1.5 \mathrm{ml} / \mathrm{min}$.

\section{Test system}

Six-week-old F344 rats (weight range; $102.25 \sim 122.28 \mathrm{~g} / \mathrm{male}$, $93.94 \sim 108.21 \mathrm{~g} /$ female) were purchased from Japan SLC Inc. (3371-8 Kotoh-cho, Hamamatsu, Shizuoka Prefecture 431-1103) and used. Only animals with no abnormalities were used after one week of acclimatization and quarantine period after arriving at the research institute. The strain used in this study was selected because a large amount of test basic data were accumulated, so it was easy to interpret and evaluate the test results. During the test period, the test animals were individually housed in a 6 wire mesh cage (W240 $\times$ L1200 $\times$ H200 $\mathrm{mm}$ ), and free intake of feed (Teklad Certified Irradiated Global 18\% Protein Rodent Diet 2918C, ENVIGO RMS Inc., U.S.A.) and water (tap water passed through microfilter and UV water sterilization device). The breeding environment of the animal room was operated by setting the temperature $\left(19 \sim 25^{\circ} \mathrm{C}\right)$, humidity $(30 \sim 70 \%)$, lighting (light and dark cycle 12 hours/day), illuminance (150 300 lux), and ventilation frequency ( $0 \sim 15$ time/hour).

\section{Experimental design}

The acute toxicity of DMC in rats is low with an LD50 of $12,900 \mathrm{mg} / \mathrm{kg}$ for oral exposure and $>38,000 \mathrm{ppm}$ for inhalation exposure. In addition, it is slightly irritating to the rabbit's eyes and does not irritate the rabbit's skin [9]. Therefore, in this study, the maximum concentration that can be exposed in the 28-day repeated inhalation toxicity study, $5000 \mathrm{ppm}$, was set as a high concentration, and then a common ratio of about 3 was applied to set the medium concentration (1600 $\mathrm{ppm}$ ) and the low concentration (600 ppm). In addition, a control group not exposed to the test substance was added. After quarantine and acclimatization, the test animals were selected by 20 males and females with no abnormalities, and then 5 animals were placed per group using the pristima system so that the average weight of each test group was equal.

\section{Observation}

During the exposure period, general symptoms including death, moribund, changes in appearance and behavior were observed daily, and body weight and food consumption were measured weekly. After the end of the exposure period, all organs in the abdominal and thoracic cavities were visually observed at autopsy, and the following organs were harvested, weighed, fixed, and histopathological examination was performed; adrenal glands, lungs, brain, ovaries, epididymis, spleen, heart, testicles, kidneys, thymus, liver, uterus.

\section{Measurement}

Prior to necropsy, all surviving animals were fasted for about 16 hours (with free access to water) and blood was collected from the abdominal aorta under isoflurane inhalation anesthesia. About $0.5 \mathrm{ml}$ of collected blood was tested for the following parameters using a hemocytometer (ADVIA 2120i, SIEMENS, Germany): white blood cell (WBC), count of differential WBC, red blood cell (RBC), hemoglobin (HGB), hematocrit (HCT), mean corpuscular volume (MCV), mean 
corpuscular hemoglobin $(\mathrm{MCH})$, mean corpuscular hemoglobin concentration (MCHC), platelet (PLT), reticulocyte (RET). For $1.0 \mathrm{~mL}$ blood, the blood clotting time prothrombin time (PT) and activated partial thromboplastin time (APTT) were measured using a clotting time analyzer (ACL-ELITE, Instrumentation Laboratory, USA). The remaining blood of the collected blood was left at room temperature for at least 30 minutes and then centrifuged (about $3,000 \mathrm{rpm}, 10 \mathrm{minutes}, 4^{\circ} \mathrm{C}$ ) to separate the serum. For this serum, the following parameters were analyzed using a biochemical analyzer (TBA-120FR, Toshiba Co., Japan): aspartate aminotransferase (AST), alanine aminotransferase (ALT), alkaline phosphatase (ALP), glucose (GLU), total protein (TP), albumin (ALB), total cholesterol (TCHO), triglyceride (TG), blood urea nitrogen (BUN), total bilirubin (TBIL), creatinine (CREA), sodium $(\mathrm{Na})$, chloride $(\mathrm{Cl})$, potassium $(\mathrm{K})$, calcium $(\mathrm{Ca})$, inorganic phosphate (IP), albumin/globulin $(\mathrm{A} / \mathrm{G})$ ratio. Necropsy was performed on the animals after blood collection.

\section{Statistical analysis}

Statistical processing of the collected data was presented as an arithmetic mean and standard deviation for each test group. The results of the body weight, food consumption, organ weight, hematologic and blood biochemical tests were conducted by Levene's test as an equal variance test, and in the case of equal variance, a one-way analysis of variance (ANOVA) test was performed, and then Dunnett LSD Test was performed as a post-test. In the case of not equal variance, the Kruskal-Wallis test was performed and the Dunn Rank Sum Test was performed as a post-test.

\section{Results and Discussion}

Dimethyl carbonate is a chemical that has recently attracted attention as an eco-friendly chemical because of its low toxicity. Phosgene is a representative toxic substance, but due to its unique reactivity, more than 2.7 million tons are used annually as a raw material for carbamates, isocyanates, polyurethanes, dialkyl carbonates, diaryl carbonates, polycarbonates and other fine chemical products. However, phosgene has many problems such as severe toxicity, corrosiveness, and processing of $\mathrm{HCl}$, an additional substance generated when used. Due to these problems, the use of DMC as a substitute for phosgene is increasing. In addition, dimethyl carbonate is used as an addition agent to increase the octane value of automobile fuels, and the oxygen content is $53 \%$, which is more than three times higher than the oxygen content of MTBE, a typical octane value improver, so the use of dimethyl carbonate is expected to increase explosively. Although many exposures of dimethyl carbonate are expected, there is no information on toxicity from inhalation exposure. Therefore, this study was conducted to evaluate the toxic reaction that occurs when repeated inhalation exposure of dimethyl carbonate to F344 rats for 28 days.

\section{Nominal and analytical concentrations}

During the exposure period, the average concentrations of dimethyl carbonate in the chambers of the T1, T2 and T3 test groups were 599.26 $\pm 31.40,1614.64 \pm 80.79$ and $5106.83 \pm 297.13$ ppm (Figure 2), and the nominal concentrations were $661.07 \pm 74.08,1858.99 \pm 120.66$ and $5746.87 \pm 157.45$ calculated, respectively. The T95, which is the time to reach the $95 \%$ concentration of the target concentrations in the chamber of 600,1600 and 5000 ppm, was identified as $16.0,18.5$ and 17.5 minutes. The results of these analysis are judged to be well exposed to the experimental animals to meet the purpose of this study.

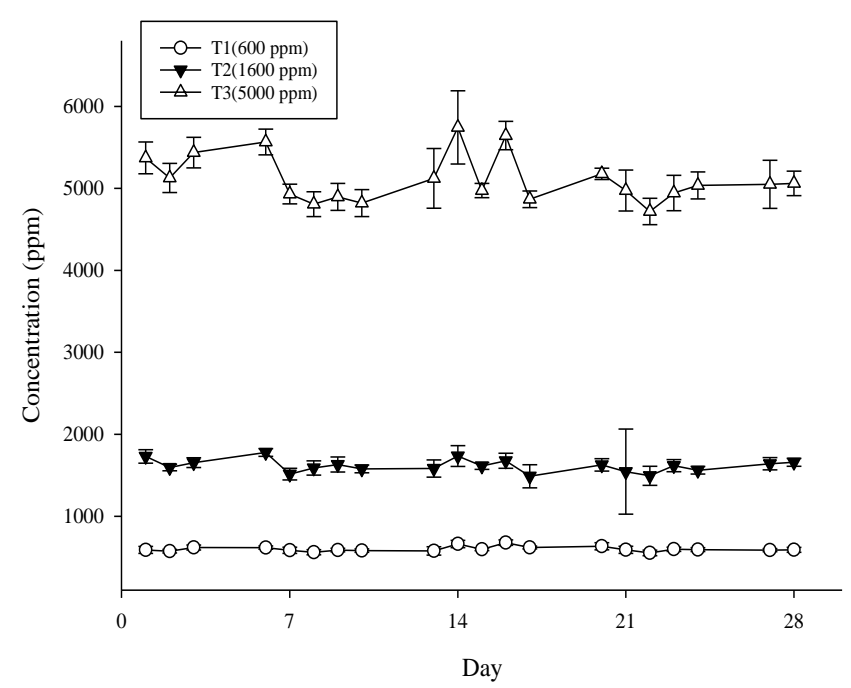

Figure 2. Average concentration of dimethyl carbonate in the whole body exposure chamber analyzed by gas chromatography during exposure period. 


\section{Clinical signs, body weights and food consumption}

There were no animals with death and general symptoms observed during the exposure period, and in the weight change, statistically significant $(\mathrm{p}<0.05)$ weight loss was only observed in the male $\mathrm{T} 2$ test group compared to the control group on the exposure start date (1 day). Other than this, no statistically significant weight change was observed (Figure 3 ). As a result of measuring the food consumption, statistically significance $(\mathrm{p}<0.05)$ was observed in the male T1 and T2 test groups compared to the control group at 4 weeks. However, other than this, no statistically significant change in food consumption was observed (Figure 4). In the body weight change, the statistically significant weight loss observed in the T2 test group at the start of exposure was the body weight before the start of exposure, and since no significant change was observed thereafter, it was judged as a change not related to exposure to the test substance. The statistically significant decrease in food consumption observed in the T1 and T2 test groups at 4 weeks of exposure was not observed depending on the exposure concentration, and the degree of change was small, so it was not judged as a change related to the exposure of the test substance.

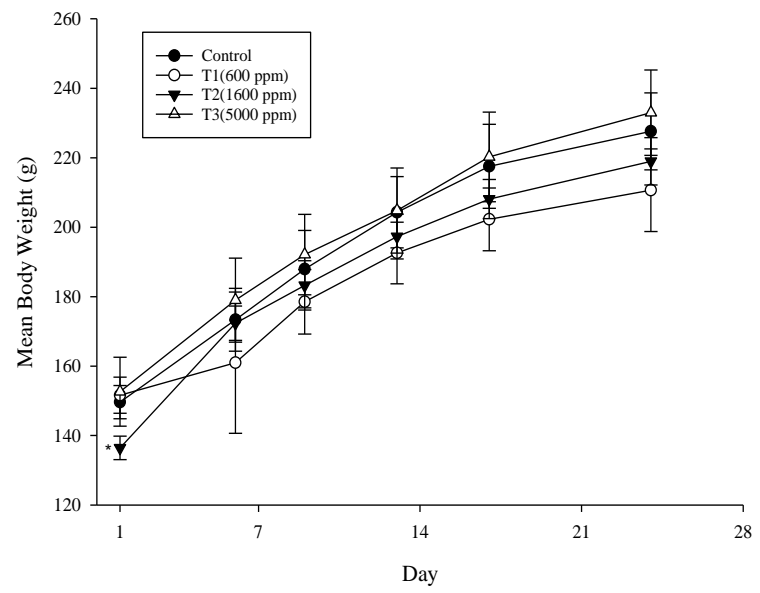

(a)

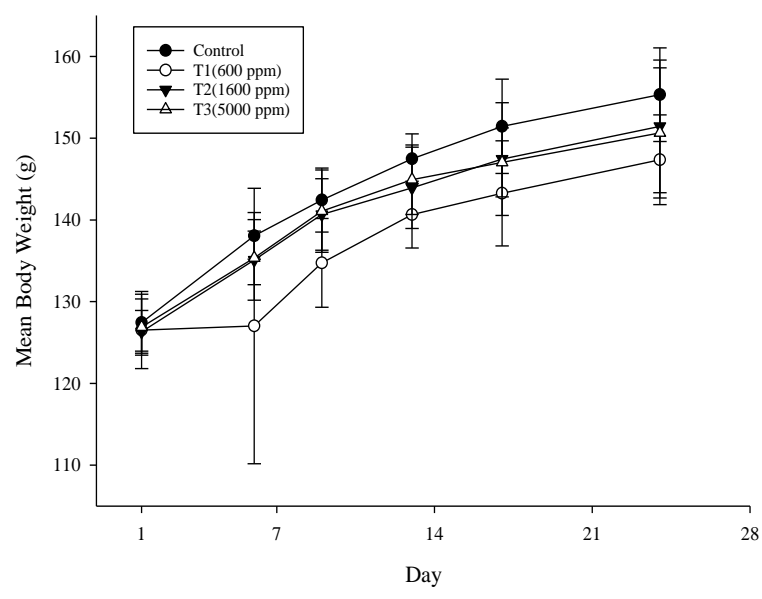

(b)

Figure 3. Changes in body weights of F344 rats exposed to dimethyl carbonate during the exposure period. OneWay ANOVA: Post Hoc-Dunnett LSD Test was applied to compare mean bodyweights between all groups. ${ }^{*} \mathrm{p}<0.05$ compared to control group. (a) male; (b)female.

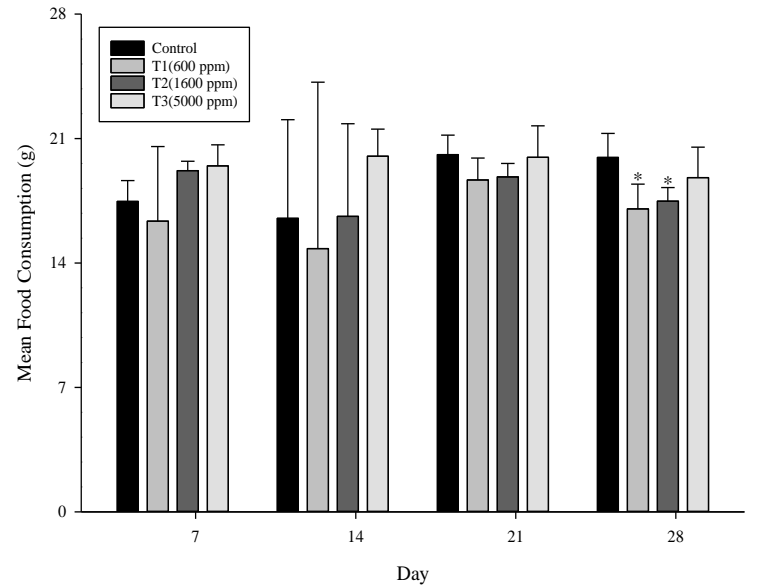

(a)

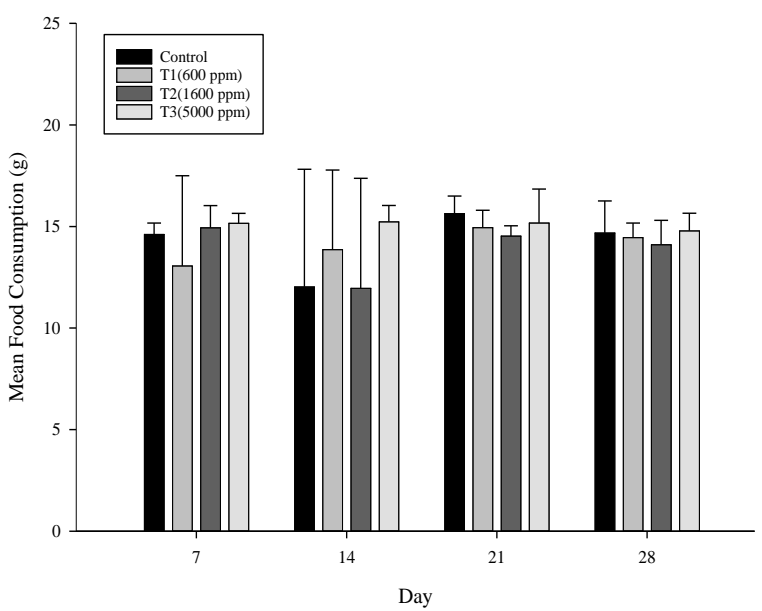

(b)

Figure 4. Changes in food consumption of F344 rats exposed to dimethyl carbonate during exposure period. OneWay ANOVA: Post Hoc-Dunnett LSD Test was applied to compare mean body weights between all groups. ${ }^{*} \mathrm{p}<0.05$ compared to control group. (a) male; (b)female. 


\section{Hematology and serum biochemistry}

As a result of hematological examination, in the males, the average red blood cell volume (MCV), reticulocyte ratio (RET\%) and number (RETA), partially active thromboplastin time (APTT) and prothrombin time (PT) of the T3 test group, the mean erythrocyte hemoglobin concentration (MCHC), RETA and APTT of the T2 test group, and the MCHC, RET\% and RETA of the T1 test group showed statistically significant ( $p<0.05$ or 0.01 ) changes compared to the control muscle. In the females, statistically significant ( $p<0.05$ or 0.01 ) changes in the MCV, platelet count (PLT), lymphocyte count (LYMA) and PT of the T3 test group, PT of the T2 test group, red blood cell count (RBC) and PT of the T1 test group compared to the control group were observed.

As a result of blood biochemical tests, in the males, the statistically significant $(p<0.05)$ changes were observed in the alanine aminotransferase (ALT) of the T2 test group, the chlorine $(\mathrm{Cl})$ and triglyceride (TG) of the T1 test group compared to the control group. In the females, the statistically significant $(\mathrm{p}<0.05$ or 0.01$)$ changes compared to the control group were observed in the total protein (TP), calcium (Ca), aspartate aminotransferase (AST), ALT and alkaline phosphatase (ALP) of the T3 test group, the ALP of the T2 test group, and the TP and ALP of the T1 test group (Table 1).

Table 1. Hematologic and serum biochemical parameters of F344 rats exposed to dimethyl carbonate.

\begin{tabular}{|c|c|c|c|c|c|c|c|c|}
\hline \multirow{2}{*}{$\begin{array}{c}\text { Sex } \\
\text { Group (ppm) }\end{array}$} & \multicolumn{4}{|c|}{ Male } & \multicolumn{4}{|c|}{ Female } \\
\hline & $C(0)$ & T1(600) & T2(1600) & T3(5000) & $\mathrm{C}(0)$ & $\mathrm{T} 1(600)$ & T2(1600) & T3(5000) \\
\hline \multicolumn{9}{|l|}{ Hematology } \\
\hline $\mathrm{WBC}\left(\times 10^{3} / \mu \mathrm{L}\right)$ & $4.14 \pm 0.66$ & $3.66 \pm 0.75$ & $4.19 \pm 1.16$ & $3.57 \pm 0.99$ & $2.84 \pm 0.52$ & $2.94 \pm 0.48$ & $2.63 \pm 0.50$ & $2.480 \pm 0.65$ \\
\hline $\mathrm{RBC}\left(\times 10^{6} / \mu \mathrm{L}\right)$ & $8.63 \pm 0.25$ & $8.67 \pm 0.24$ & $8.74 \pm 0.09$ & $8.70 \pm 0.27$ & $8.18 \pm 0.62$ & $8.87 \pm 0.25^{*} \mathrm{D}$ & $8.64 \pm 0.12$ & $8.724 \pm 0.24$ \\
\hline HGB (g/dL) & $14.52 \pm 0.36$ & $14.76 \pm 0.39$ & $14.90 \pm 0.07$ & $14.66 \pm 0.56$ & $14.44 \pm 0.87$ & $15.44 \pm 0.49$ & $15.18 \pm 0.23$ & $15.12 \pm 0.47$ \\
\hline HCT (\%) & $42.70 \pm 1.19$ & $42.60 \pm 0.81$ & $42.92 \pm 0.35$ & $42.34 \pm 1.00$ & $41.92 \pm 1.44$ & $44.06 \pm 1.15$ & $43.06 \pm 0.66$ & $43.02 \pm 1.02$ \\
\hline $\mathrm{MCV}(\mathrm{fL})$ & $49.46 \pm 0.18$ & $49.20 \pm 0.49$ & $49.10 \pm 0.14$ & $48.68 \pm 0.41^{+\mathrm{D}}$ & $51.38 \pm 2.48$ & $49.64 \pm 0.31$ & $49.82 \pm 0.35$ & $49.30 \pm 0.32+R$ \\
\hline $\mathrm{MCH}(\mathrm{pg})$ & $16.82 \pm 0.13$ & $17.06 \pm 0.11$ & $17.06 \pm 0.11$ & $16.86 \pm 0.25$ & $17.64 \pm 0.34$ & $17.40 \pm 0.25$ & $17.56 \pm 0.13$ & $17.34 \pm 0.13$ \\
\hline $\mathrm{MCHC}(\mathrm{g} / \mathrm{dL})$ & $33.98 \pm 0.38$ & $34.68 \pm 0.34^{*} \mathrm{D}$ & $34.76 \pm 0.21^{*} \mathrm{D}$ & $34.62 \pm 0.61$ & $34.42 \pm 1.028$ & $35.00 \pm 0.37$ & $35.26 \pm 0.37$ & $35.10 \pm 0.43$ \\
\hline $\operatorname{PLT}\left(\times 10^{3} / \mu \mathrm{L}\right)$ & $739.8 \pm 53.76$ & $689.8 \pm 43.58$ & $669.2 \pm 35.78$ & $664.2 \pm 59.12$ & $895.0 \pm 188.02$ & $720.0 \pm 85.40$ & $730.0 \pm 23.67$ & $699.4 \pm 54.28^{*} \mathrm{D}$ \\
\hline RET (\%) & $2.45 \pm 0.25$ & $1.84 \pm 0.22^{+\mathrm{D}}$ & $2.05 \pm 0.27$ & $1.784 \pm 0.24^{+\mathrm{D}}$ & $4.39 \pm 5.28$ & $2.20 \pm 0.10$ & $2.00 \pm 0.16$ & $1.98 \pm 0.223$ \\
\hline RET $\left(\times 10^{3} / \mu \mathrm{L}\right)$ & $210.88 \pm 17.22$ & $159.06 \pm 15.58^{+\mathrm{D}}$ & $178.74 \pm 22.7^{*} \mathrm{D}$ & $154.68 \pm 16.68^{+D}$ & $333.58 \pm 361.21$ & $194.68 \pm 9.13$ & $172.76 \pm 13.46$ & $172.4 \pm 16.27$ \\
\hline APTT (sec) & $16.80 \pm 1.11$ & $18.14 \pm 0.34$ & $18.30 \pm 1.19^{*} \mathrm{D}$ & $18.56 \pm 0.54^{*} \mathrm{D}$ & $16.18 \pm 0.56$ & $16.56 \pm 0.61$ & $15.74 \pm 2.01$ & $15.50 \pm 1.64$ \\
\hline $\mathrm{PT}(\mathrm{sec})$ & $10.24 \pm 0.27$ & $10.34 \pm 0.29$ & $10.70 \pm 0.30$ & $11.44 \pm 0.59+\mathrm{D}$ & $9.86 \pm 0.15$ & $10.70 \pm 0.47^{+\mathrm{D}}$ & $11.24 \pm 0.37+\mathrm{D}$ & $11.38 \pm 0.42^{+D}$ \\
\hline \multicolumn{9}{|c|}{ Serum biochemistry } \\
\hline $\mathrm{Na}(\mathrm{mmol} / \mathrm{L})$ & $143.50 \pm 1.38$ & $144.58 \pm 1.74$ & $143.40 \pm 1.58$ & $142.14 \pm 2.31$ & $142.84 \pm 0.75$ & $143.84 \pm 1.03$ & $144.14 \pm 0.91$ & $142.04 \pm 1.23$ \\
\hline $\mathrm{K}(\mathrm{mmol} / \mathrm{L})$ & $3.94 \pm 0.24$ & $4.00 \pm 0.17$ & $4.02 \pm 0.30$ & $3.86 \pm 0.35$ & $4.00 \pm 0.10$ & $3.94 \pm 0.06$ & $3.92 \pm 0.23$ & $3.82 \pm 0.22$ \\
\hline $\mathrm{Cl}(\mathrm{mmol} / \mathrm{L})$ & $100.78 \pm 0.99$ & $103.06 \pm 1.21^{*} \mathrm{D}$ & $101.88 \pm 1.27$ & $100.12 \pm 1.19$ & $104.66 \pm 0.79$ & $104.16 \pm 1.59$ & $104.84 \pm 1.21$ & $102.88 \pm 1.09$ \\
\hline $\mathrm{TP}(\mathrm{g} / \mathrm{dL})$ & $5.86 \pm 0.11$ & $5.76 \pm 0.11$ & $5.76 \pm 0.09$ & $5.72 \pm 0.11$ & $6.00 \pm 0.07$ & $5.76 \pm 0.11+\mathrm{D}$ & $5.92 \pm 0.13$ & $5.80 \pm 0.12^{*} \mathrm{D}$ \\
\hline $\mathrm{Ca}(\mathrm{mg} / \mathrm{dL})$ & $10.18 \pm 0.13$ & $10.00 \pm 0.22$ & $9.96 \pm 0.21$ & $9.84 \pm 0.32$ & $10.00 \pm 0.07$ & $9.84 \pm 0.15$ & $9.82 \pm 0.15$ & $9.78 \pm 0.08^{*} \mathrm{D}$ \\
\hline $\mathrm{TG}(\mathrm{mg} / \mathrm{dL})$ & $62.48 \pm 14.65$ & $41.50 \pm 3.90^{*} \mathrm{D}$ & $53.64 \pm 8.78$ & $46.16 \pm 11.63$ & $20.76 \pm 11.87$ & $15.96 \pm 4.53$ & $17.38 \pm 3.24$ & $16.44 \pm 6.52$ \\
\hline AST (IU/L) & $81.84 \pm 3.83$ & $81.00 \pm 6.39$ & $76.28 \pm 2.02$ & $83.46 \pm 5.19$ & $85.64 \pm 5.27$ & $94.48 \pm 8.76$ & $97.10 \pm 11.92$ & $102.82 \pm 4.77^{\star D}$ \\
\hline ALT (IU/L) & $39.16 \pm 0.92$ & $36.90 \pm 0.71$ & $36.04 \pm 2.10^{*} \mathrm{R}$ & $38.88 \pm 2.13$ & $37.10 \pm 3.95$ & $37.74 \pm 3.41$ & $41.84 \pm 3.71$ & $43.36 \pm 3.31^{*} \mathrm{D}$ \\
\hline ALP (IU/L) & $667.36 \pm 21.62$ & $641.56 \pm 23.04$ & $657.44 \pm 52.39$ & $664.54 \pm 45.17$ & $492.06 \pm 42.26$ & $601.78 \pm 54.43^{+\mathrm{D}}$ & $572.74 \pm 36.34^{*} \mathrm{D}$ & $655.12 \pm 50.57+\square$ \\
\hline
\end{tabular}

1 The values are expressed as mean \pm SD ( $n=5$ males and 5 females per group).

${ }^{2} \mathrm{D}=$ Dunnett LSD Test Significant at the 0.05 level, $+\mathrm{D}=$ Dunnett LSD Test Significant at the 0.01 level.

${ }^{3} \mathrm{R}=$ Dunn Rank Sum Test Significant at the 0.05 level, $+\mathrm{R}=$ Dunn Rank Sum Test Significant at the 0.01 level.

DMC is hydrolyzed to carbon dioxide and methanol through esterases in the environment and in the body [18], and methanol is sequentially oxidized to formaldehyde and formic acid [19]. In the repeated oral administration of methanol in SD rats, an increase in AST and ALP was observed, and no histopathological changes were observed [20]. PT tests factors such as FII, FV, FVII, FX and fibrinogen, and APTT is a factor considered as a good screening test for FVIII, FIX, FXI and FXII defects. These clotting factors are synthesized in the liver [21]. In this study, statistically significant increases were observed in AST, ALP, APTT, and PT values, but there were no related histopathological findings, and there was no significant change in AST and TBIL levels, and the values of AST and ALP did not show an increase of more than 2 3 times. In addition, APTT and PT levels were not judged to be toxicological changes because they showed an increase of less than 
2 seconds [22]. Except for these changes, statistically significant changes have no concentration dependence, and the degree of change is small, so it is judged that there is no toxicological significance [23].

\section{Organ weights, necropsy and histopathological findings}

In the absolute organ weight change, statistical significance $(\mathrm{p}<0.05$ or 0.01$)$ was observed in the liver and lungs of the T2 group and liver and spleen in the T1 group in males, and in the heart and liver of the T1 group in females. Regarding the change in relative organ weight, statistical significance ( $p<0.05$ or 0.01 ) was observed in the livers of male T1 and T2 groups (Table 2).

As a result of necropsy after the end of exposure, no animals showed gross findings, and no findings related to exposure to the test substance were observed in the histopathological examination results except for spontaneous: the aggregates, macrophage, foamy, infiltration of mononuclear cells, fibrosis and hemorrhage in the lungs, the infiltration of monocytes in the liver, and the calcification in the heart, and the cyst in the ultimobranchial duct in the thyroid.

Table 2. Absolute and relative organ weights of F344 rats exposed to dimethyl carbonate.

\begin{tabular}{|c|c|c|c|c|c|c|c|c|}
\hline \multirow{2}{*}{$\frac{\text { Sex }}{\text { Group (ppm) }}$} & \multicolumn{4}{|c|}{ Male } & \multicolumn{4}{|c|}{ Female } \\
\hline & $\mathrm{C}(0)$ & $\mathrm{T} 1(600)$ & T2(1600) & T3(5000) & $\mathrm{C}(0)$ & $\mathrm{T} 1(600)$ & $\mathrm{T} 2(1600)$ & T3(5000) \\
\hline \multicolumn{9}{|c|}{ Absolute organ weight (g) } \\
\hline Brain & $1.83 \pm 0.04$ & $1.79 \pm 0.03$ & $1.79 \pm 0.039$ & $1.82 \pm 0.05$ & $1.69 \pm 0.04$ & $1.70 \pm 0.02$ & $1.68 \pm 0.04$ & $1.70 \pm 0.02$ \\
\hline Heart & $0.66 \pm 0.06$ & $0.62 \pm 0.03$ & $0.65 \pm 0.02$ & $0.68 \pm 0.04$ & $0.51 \pm 0.02$ & $0.47 \pm 0.02^{+\mathrm{D}}$ & $0.49 \pm 0.01$ & $0.51 \pm 0.01$ \\
\hline Kidneys & $1.59 \pm 0.14$ & $1.41 \pm 0.07$ & $1.46 \pm 0.06$ & $1.55 \pm 0.12$ & $1.11 \pm 0.04$ & $1.08 \pm 0.02$ & $1.11 \pm 0.03$ & $1.13 \pm 0.04$ \\
\hline Liver & $6.89 \pm 0.60$ & $5.64 \pm 0.57+\mathrm{D}$ & $6.02 \pm 0.30^{*} \mathrm{D}$ & $6.45 \pm 0.43$ & $4.30 \pm 0.24$ & $3.96 \pm 0.12^{*} \mathrm{D}$ & $4.07 \pm 0.18$ & $4.20 \pm 0.16$ \\
\hline Lung & $0.38 \pm 0.03$ & $0.37 \pm 0.029$ & $0.33 \pm 0.02^{*} \mathrm{D}$ & $0.38 \pm 0.03$ & $0.32 \pm 0.03$ & $0.31 \pm 0.02$ & $0.30 \pm 0.02$ & $0.31 \pm 0.02$ \\
\hline Spleen & $0.53 \pm 0.06$ & $0.44 \pm 0.04^{*} \mathrm{D}$ & $0.47 \pm 0.04$ & $0.49 \pm 0.03$ & $0.38 \pm 0.04$ & $0.35 \pm 0.02$ & $0.36 \pm 0.02$ & $0.38 \pm 0.03$ \\
\hline \multicolumn{9}{|c|}{ Relative organ weight (\%) } \\
\hline Brain & $0.82 \pm 0.04$ & $0.89 \pm 0.04^{*} \mathrm{D}$ & $0.85 \pm 0.02$ & $0.82 \pm 0.05$ & $1.17 \pm 0.049$ & $1.22 \pm 0.060$ & $1.22 \pm 0.05$ & $1.22 \pm 0.058$ \\
\hline Heart & $0.30 \pm 0.02$ & $0.30 \pm 0.02$ & $0.31 \pm 0.01$ & $0.31 \pm 0.01$ & $0.36 \pm 0.02$ & $0.34 \pm 0.016$ & $0.36 \pm 0.01$ & $0.36 \pm 0.02$ \\
\hline Kidneys & $0.71 \pm 0.03$ & $0.70 \pm 0.01$ & $0.69 \pm 0.01$ & $0.70 \pm 0.02$ & $0.77 \pm 0.02$ & $0.78 \pm 0.05$ & $0.80 \pm 0.01$ & $0.81 \pm 0.03$ \\
\hline Liver & $3.08 \pm 0.10$ & $2.79 \pm 0.12^{+\mathrm{D}}$ & $2.86 \pm 0.06^{*} \mathrm{D}$ & $2.90 \pm 0.16$ & $2.99 \pm 0.13$ & $2.86 \pm 0.19$ & $2.95 \pm 0.05$ & $3.00 \pm 0.08$ \\
\hline Lung & 0.170 .01 & $0.19 \pm 0.02$ & $0.16 \pm 0.01$ & $0.17 \pm 0.01$ & $0.22 \pm 0.02$ & $0.22 \pm 0.01$ & $0.22 \pm 0.01$ & $0.22 \pm 0.01$ \\
\hline Spleen & $0.24 \pm 0.02$ & $0.22 \pm 0.01$ & $0.22 \pm 0.01$ & $0.22 \pm 0.01$ & $0.26 \pm 0.03$ & $0.25 \pm 0.02$ & $0.26 \pm 0.01$ & $0.27 \pm 0.02$ \\
\hline
\end{tabular}

1 The values are expressed as mean \pm SD ( $n=5$ males and 5 females per group).

${ }^{2} \mathrm{D}=$ Dunnett LSD test significant at the 0.05 level, $+\mathrm{D}=$ Dunnett LSD test significant at the 0.01 level.

\section{Conclusions}

In order to evaluate the toxic reaction that occurs during 28 days repeated inhalation exposure of dimethyl carbonate, the test substance was systemically inhaled to F344 rats at concentrations of 600, 1600, and 5000 ppm. As a result, the levels of APTT and PT, which are variables related to blood coagulation time, and AST and ALP levels of the serum biochemical test were increased. These changes are thought to be the effect of methanol, one of the metabolites of dimethyl carbonate, on the liver. Therefore, the target organ was judged to be the liver, and no toxic effects related to the test substance were observed under this test condition, so the NOAEC (No Observed Adverse Effect Concentration) value was not confirmed. However, exposure-related effects were observed at PT and ALP levels up to an exposure concentration of 600 ppm, and NOEC (No Observed Effect Concentration) was determined to be less than 600 ppm. Therefore, dimethyl carbonate is considered a safer chemical than phosgene with an LD 50 of $2.1 \mathrm{ppm}$ in rats and an LOAEL of 0.1 ppm upon repeated inhalation exposure [24], and is considered an excellent substitute for phosgene.

\section{Acknowledgement}

The author thanks to the Occupational Safety and Health Research Institute for providing financial support.

\section{Conflict of interest}

The author declares no conflict of interest.

\section{ORCID}

Dongseok Seo: 0000-0002-3853-9744 


\section{References}

[1] Zhang G, Liu K, Ling X, Wang Z, Zou P, Wang X, et al. DBP-induced endoplasmic reticulum stress in male germ cells causes autophagy, which has a cytoprotective role against apoptosis in vitro and in vivo. Toxicol Lett 2016;245:86-98. https://doi.org/10.1016/j.toxlet.2016.01.016

[2] Office of Environmental Health Hazard Assessment (OEHHA). Appendix B: OEHHA final revised assessment. Final revised health assessment for dimethyl carbonate. Assessed on Nov 18, 2010. http://www.valleyair.org/Workshops/postings/2010/12-29-10/04\%20AppB\%20OEHHA\%20assessment.pdf

[3] Li D, Fang W, Xing Y, Guo Y, Lin R. Effects of dimethyl or diethyl carbonate as an additive on volatility and flash point of an aviation fuel. J Haz Mater 2009;161(2-3):1193-1201. https://doi.org/10.1016/j.jhazmat.2008.04.070

[4] Inamoto K, Hasegawa C, Hiroya K, Kondo Y, Osako T, Uozumi Y, et al. Use of dimethyl carbonate as a solvent greatly enhances the biaryl coupling of aryl iodides and organoboron reagents without adding any transition metal catalysts. Chem Commun 2012;48(23):2912-2914. https://doi.org/10.1039/C2CC17401D

[5] American K. Dimethyl Carbonate (DMC) The newest VOC exempt solvent. 2009. https://documen.site/download/dimethyl-carbonate-kowa-company-ltd_pdf

[6] Memoli S, Selva M, Tundo P. Dimethylcarbonate for eco-friendly methylation reactions. Chemosphere 2001;43(1):115121. https://doi.org/10.1016/S0045-6535(00)00331-3

[7] Miao X, Fischmeister C, Bruneau C, Dixneuf PH. Dimethyl carbonate: An eco-friendly solvent in ruthenium-catalyzed olefin metathesis transformations. Chem Sus Chem 2008;1(10):813-816. https://doi.org/10.1002/cssc.200800074

[8] Fabbri D, Baravelli V, Chiavari G, Prati S. Dimethyl carbonate as a novel methylating reagent for fatty acids in analytical pyrolysis. J Chromatog A 2005;1065(2):257-264.https://doi.org/10.1016/j.chroma.2004.12.077

[9] Song C, Zhang Z, Chen X, Zhang Y, Wang C, Liu K. Study on three kinds of gasoline oxygenates-induced DNA damage in mice fibroblasts. Zhonghua Lao Dong Wei Sheng Zhi Ye Bing Za Zhi 2002;20(5):362-364.

https://pubmed.ncbi.nlm.nih.gov/14694727/

[10] Exxon Corporation. Inhalation development toxicity study in mice with dimethylcarbonate. Final report. Exxon Corporation; East Millstone NJ.1992. Project Number 107334.

[11] Bevan CB. Developmental toxicity evaluation of dimethylcarbonate by inhalation in CD-1 mice. Int Toxicol 1995;7:72.

[12] Rogers JM, Mole ML, Chernoff N, Barbee BD, Turner CI, Logsdon TR, et al. The developmental toxicity of inhaled methanol in the CD-1 mouse, with quantitative dose-response modeling for estimation of benchmark doses. Teratology 1993;47(3):175-188. https://doi.org/10.1002/tera.1420470302

[13] Lewis RJ. Sax's dangerous properties of industrial materials. 9th ed. Volumes 1-3. Van Nostrand Reinhold, New York 1996, 2205.

[14] Hazardous Substances Data Bank (HSDB). Dimethyl carbonate. https://pubchem.ncbi.nlm.nih.gov/compound/Dimethy-carbonate.

[15] National Toxicology Program (NTP). NIH technical report, Number 19. Toxicity studies of formic acid administered by inhalation to F344/N rats and B6C3F1 mice. Assessed on July 1992. https://ntp.niehs.nih.gov/ntp/htdocs/st rpts/tox019.pdf

[16] Agency for toxic substances and disease registry (ATSDR) toxicological profile information, U.S. Department of Health and Human Services 1999;25(12):743-746. https://doi.org/10.1177/074823379901500809

[17] National Toxicology Program (NTP). NIH Publication No. 03-4478. NTP-CERHR monograph on the potential human reproductive and developmental effects of methanol. Assessed on Sept 2003. https://ntp.niehs.nih.gov/ntp/ohat/methanol/methanol monograph.pdf.

[18] Kowa American Corporation. Dimethyl carbonate information request. Submitted by Mark K. Smith. 2009. https://www.aqmd.gov/docs/default-source/planning/1168/dmc oehha memo.pdf?sfvrsn=4

[19] Office of Environmental Health Hazard Assessment (OEHHA). OEHHA final revised assessment. OEHHA final revised health assessment for dimethyl carbonate. Assessed on Nov 18, 2010.

https://www.aqmd.gov/docs/default-source/planning/1168/dmc oehha_memo.pdf?sfvrsn=4. 
[20] United States Environmental Protection Agency (U.S. EPA). Toxicological review of methanol(noncancer). Assessed on Sept 2013. https://cfpub.epa.gov/ncea/iris/iris documents/documents/toxreviews/0305tr.pdf

[21] Teddy CA, Everton E, Osaro E. Evaluation of coagulation parameters and liver enzymes among alcohol drinkers in Port Harcourt. Nigeria. Int J Gen Med 2013;6:489. https://doi.org/10.2147/IJGM.S43472

[22] Food and Drug Administration (FDA). Guidance for industry drug-induced liver injury: Premarketing clinical evaluation. Assessed on July 2009. https://www.fda.gov/media/116737/download

[23] Matsuzawa T, Nomur M, Unno T. Clincal pathology reference ranges of laboratory animals. J Vet Med Sci 1993; 55(3):351-362. https://doi.org/10.1292/jvms.55.351

[24] European Commission, Employment social affairs and inclusion. Recommendation from the scientific committee on occupational exposure limits for phosgene. SCOEL/SUM/004. Assessed on Sept 2011.

https://www.google.co.kr/url?sa=t\&rct=j\&q=\&esrc=s\&source=web\&cd=\&ved=2ahUKEwje1YmvgInxAhVtw4sBHbI1C5 gQFjABegQIAxAD\&url=http \%3A\%2F\%2Fec.europa.eu \%2Fsocial\%2FBlobServlet $\% 3$ FdocId $\% 3 D 7302 \% 26$ langId $\% 3$ Den \&usg=AOvVaw3VHjfgidp31K1yZ-moSIs 